\title{
Anti-inflammatory effects of 1,25-dihydroxyvitamin D3 in monocytes cultured in serum from patients with type 2 diabetes mellitus and diabetic nephropathy with uremia via Toll-like receptor 4 and nuclear factor- $k B$ p65
}

\author{
MENGXUE YANG ${ }^{1}$, JIE XU $^{2}$, JIE YU $^{2}$, BO YANG $^{1}$, HUA GAN $^{3}$, SICHENG LI $^{1}$ and XIANWEN LI ${ }^{1}$ \\ ${ }^{1}$ Department of Endocrinology, The First Affiliated Hospital of Zunyi Medical College; \\ ${ }^{2}$ School of Public Health, Zunyi Medical College, Zunyi, Guizhou 563003; ${ }^{3}$ Department of Nephrology, \\ The First Affiliated Hospital of Chongqing Medical University, Chongqing 400016, P.R. China
}

Received November 24, 2014; Accepted September 9, 2015

DOI: $10.3892 / \mathrm{mmr} .2015 .4482$

\begin{abstract}
Type 2 diabetes mellitus (T2DM) and diabetic nephropathy (DN) seriously affect the quality of human life. 1,25-dihydroxyvitamin D3 (VD3) is known to exert anti-inflammatory and immunomodulatory effects. The present study investigated the effects of VD3 on Toll-like receptor 4 (TLR4) and nuclear factor (NF)- $\mathrm{B}$ p65 expression in monocytes from patients with T2DM and investigated the underlying mechanisms. Serum from subjects of the control, T2DM and DN with uremia groups was isolated, and THP-1 monocytes were cultured in these sera with or without VD3. After treatment with lipopolysaccharide (LPS) and interleukin (IL)-15, monocytes and culture supernatants were collected. The expression of TLR4, TLR9 and IL-15 mRNA was detected using reverse-transcription polymerase chain reaction analysis. Furthermore, the protein expression of TLR4, NF- $\mathrm{KB}$ p 65 and inhibitor of $\mathrm{NF}-\kappa \mathrm{B}(\mathrm{I} \kappa \mathrm{B})$ was determined using western blot analysis. The levels of IL- 6 and monocyte chemotactic protein in culture supernatants were detected using ELISAs. The impact of LPS, IL-15 and VD3 on the TLR/NF- $\kappa B$ signaling pathway in the T2DM and DN uremia groups was also investigated. In the T2DM and DN uremia groups, LPS and IL-15 downregulated the expression of $\mathrm{I} \kappa \mathrm{B}$ and upregulated levels of proteins, including TLR4, NF- $\kappa \mathrm{B}$ p65, IL-6 and monocyte chemoattractant protein 1, as well as TLR4 and IL-15 mRNA. There was no significant difference in TLR9 mRNA protein expression among the three groups. VD3 partially blocked the above effects; However, pre-treatment with VD3 had no significant effect on TLR4 mRNA expression, protein expression
\end{abstract}

Correspondence to: Miss. Mengxue Yang, Department of Endocrinology, The First Affiliated Hospital of Zunyi Medical College, 201 Dalian Road, Zunyi, Guizhou 563003, P.R. China E-mail: yangmengx123@163.com

Key words: diabetic nephropathy, uremia, monocyte, inflammation of $\mathrm{NF}-\kappa \mathrm{B}$ p65 and $\mathrm{I} \kappa \mathrm{B}$, or the levels of associated inflammatory cytokines. In conclusion, the present study indicated that anti-inflammatory effects of VD3 in inflammatory immune responses in T2DM and DN uremia are associated with the TLR4/NF- $\mathrm{B}$ p65 signaling pathway.

\section{Introduction}

Inflammation and immune response are likely to be closely associated with the occurrence and development of type 2 diabetes mellitus (T2DM) and diabetic nephropathy (DN). A study reported that monocytes from T2DM patients had a pro-inflammatory profile with a marked capacity for the expression of inflammatory cytokines (1). 1,25-dihydroxy vitamin D3 (VD3) is the active metabolite of vitamin D3, and its role in the prevention and treatment of diabetes is well known. Despite the classical role of regulating the metabolism of calcium and phosphorus in the body, VD3 can also regulate the differentiation and proliferation of numerous cell types (2); furthermore, a previous study demonstrated that vitamin D has anti-inflammatory and immunomodulatory effects (3).

Previous in vitro studies have found that vitamin D3 and its derivatives can downregulate inflammatory factors secreted by monocytes (4) and have a hyperresponsiveness to ligands, showing a time- and concentration dependence $(5,6)$. The correlation between vitamin $\mathrm{D}$ and diabetes mellitus (DM), particularly T2DM, has become the focus of current research (7).

A large number of in vivo and in vitro studies, as well as observational and interventional studies, have gradually clarified the association between vitamin $\mathrm{D}$ deficiency and the Toll-like receptor (TLR)/nuclear factor- $\kappa \mathrm{B}(\mathrm{NF}-\kappa \mathrm{B})$ signaling pathway. Thirteen members in the human TLR family have been identified, among which TLR4 has been most thoroughly studied. TLR4 is mainly expressed in lymphoid tissues, monocytes and macrophages, as well as $\mathrm{T}$ and B lymphocytes (8). Devaraj et al (9) and Dasu et al (10) found that the expression of TLR4 was increased in peripheral blood mononuclear cells (PBMC) from type 1 diabetes mellitus (T1DM) and T2DM 
patients, and that this increase was correlated with the inflammatory response $(9,10)$.

Verma et al (11) found that VD3 can upregulate the levels of TLR10 in THP-1 cells, while downregulating the levels of TLR2, -4 and -5 , which was in accordance with a study by Sadeghi et al (12). Gu et al (13) reported that VD3 downregulated pulmonary TLR4 expression in asthmatic BALB/c mice. In addition, $\mathrm{Li}$ et al (14) demonstrated that vitamin D had a protective role in diabetes-induced vascular injury and reduced TLR4 and NF- $\kappa \mathrm{B}$ expression in diabetic rats.

A previous study by our group showed that endotoxins in T2DM and DN patients were increased, and monocytes where dysfunctional when they grew in an endotoxin-containing microenvironment (15-17). As an inflammatory stimulant, lipopolysaccharide (LPS) can activate mononuclear macrophages and promote the expression of cytokines, and it was used in previous studies as a replacement for endotoxin. LPS is a ligand of TLR4, causing inflammatory cytokine disorders by producing interleukin (IL)-6, IL-15, IL-18 and IL-10 through reaction with TLR4 located on the cell surface (15-17). Interleukin-15 (IL-15) is a soluble and abundant cytokine, which is most highly expressed in monocytes and macrophages. Alleva et al (18) reported that IL-15 acts on mononuclear macrophages in an autocrine-like manner as a monokine, and that mononuclear macrophages are highly sensitive to changes in the levels of IL-15. High concentrations of IL-15 (10-1,000 ng/ml) led to increased production of pro-inflammatory cytokines, including IL-1, IL-6 and tumor necrosis factor $\alpha$, by LPS-activated mononuclear macrophages, whereas low concentrations of IL-15 $(<1.0 \mathrm{ng} / \mathrm{ml})$ selectively inhibited the production of pro-inflammatory cytokines.

A previous study by our group has demonstrated that VD3 alleviates inflammation, and that this anti-inflammatory effect may be associated with signal transducer and activator of transcription 5 (STAT5)-vitamin D receptor (VDR) crosstalk in monocytes (19). However, whether the anti-inflammatory effects of VD3 in monocytes from patients with T2DM and $\mathrm{DN}$ with uremia are associated with the TLR/NF- $\kappa \mathrm{B}$ signaling pathway has remained elusive.

The present study examined the expression of TLR4 and $\mathrm{NF}-\kappa \mathrm{B}$ in monocytes incubated in serum from patients with T2DM or undialyzed DN uremia as well as the effect of VD3 on these. The inflammatory effects of the above genes in T2DM and DN uremia and the possible mechanism for the anti-inflammatory effects of VD3 were also investigated.

\section{Subjects and methods}

Patients. From May 2009 to June 2011, 20 subjects (10 males and 10 females) were selected from the medical examination center at the First Affiliated Hospital of Chongqing Medical University (Chongqing, China) for the control group. The control subjects were volunteers who were physically healthy after examination and without a family history of diabetes. Simultaneously, patients from the Department of Nephrology and Endocrinology of Chonqing Medical University were selected to constitute the T2DM group (28 cases, including 15 males and 13 females) and the DN uremia group (30 cases, including 16 males and 14 females). The diagnosis of diabetes was performed according to the
1999 World Health Organization (WHO) diabetes diagnosis and classification standards (20). The serum levels of $25(\mathrm{OH})$ VD were 21 29 $\mathrm{ng} / \mathrm{ml}$ and the levels of glutamic acid decarboxylase antibodies (GADA) were $<1.0$. The inclusion criteria were set as fasting blood glucose $<7.0 \mathrm{mmol} / 1$ and glycosylated hemoglobin (HbAlc) $<6.5 \%$. The diagnosis of DN was consistent with the diagnostic criteria of chronic renal failure (uremia): Serum creatinine (Scr) $\geq 707 \mu \mathrm{mol} / 1$ or endogenous creatinine clearance $<10 \mathrm{ml} / \mathrm{min}$, and patients were in a stable state (Table I). The exclusion criteria were as follows: Type 1 diabetes mellitus or secondary diabetes mellitus; acute infectious diseases; cardiac or hepatic dysfunction; acute complications of diabetes or infections in the last 3 months; pregnancy or lactation; other connective tissue diseases or autoimmune diseases; tumors; cardiovascular or cerebrovascular event; asthma; and intake of drugs affecting the study. All selected subjects were unrelated individuals of Chinese Han ethnicity.

Informed consent was obtained from the patients and was approved by the ethics committee of the First Affiliated Hospital of Chongqing Medical University.

Preparation and inactivation of serum, VD3, LPS and human recombinant $I L-15$. Morning fasting venous blood from subjects was collected and analyzed in the laboratory of the First Affiliated Hospital of Chongqing Medical University, for determination of parameters associated with blood, liver and kidney function, as well as blood lipids and other blood components. After standing for $30 \mathrm{~min}$ at room temperature, $2 \mathrm{ml}$ of each blood sample was centrifuged at a low temperature at $3,000 \mathrm{~g}$ at $-4^{\circ} \mathrm{C}$ for $15 \mathrm{~min}$. The upper serum was collected, filtered and sterilized through $0.22-\mu \mathrm{m}$ microporous membranes, and separately filled into Eppendorf tubes to be stored at $-80^{\circ} \mathrm{C}$ for later use. A VD3 stock solution $\left(10^{-4}\right.$ diluted to $10^{-5}, 10^{-6}$, and $10^{-7} \mathrm{~mol} / 1$ in the preliminary experiment, respectively; Sigma-Aldrich, St. Louis, MO, USA) was prepared in 95\% ethanol, and filtered and sterilized through 0.22- $\mu \mathrm{m}$ micro-porous membranes (Millipore Millex needle-type filters; EMD Millipore, Billerica, MA, USA). It was stored in Eppendorf tubes at $-80^{\circ} \mathrm{C}$ for further use. An LPS stock solution (10 mg/ml; Sigma-Aldrich) was prepared in serum-free culture media and stored in Eppendorf tubes at $-20^{\circ} \mathrm{C}$. Human recombinant IL-15 (Peprotech, Rocky Hill, NJ, USA) was diluted with phosphate-buffered saline to $50 \mathrm{ng} / \mathrm{ml}$ and stored in Eppendorf tubes at $-20^{\circ} \mathrm{C}$.

Grouping and monocyte culture. The THP-1 cell line was provided by the Cell Bank of the Chinese Academy of Sciences (Shanghai, China). Prior to intervention, THP-1 cells in the logarithmic growth phase were selected and, after the culture solution was aspirated, the cells were re-suspended in RPMI-1640 (Gibco; Thermo Fisher Scientific, Inc., Waltham, MA, USA) culture medium, containing $2 \%$ fetal bovine serum and benzylpenicillin and streptomycin $100 \mathrm{IU} / \mathrm{ml}$; (GE Healthcare Life Sciences, Logan, UT, USA) and counted. Cells were incubated in six-well culture plates at $5 \times 10^{5}$ cells $/ \mathrm{ml}$. Following culture at $37^{\circ} \mathrm{C}$ in a $5.0 \% \mathrm{CO}_{2}$ incubator for $24 \mathrm{~h}$, serum from individual subjects (three) from the three groups were added to the cells at a concentration of $5.0 \%$, with a total of three wells used for each experimental condition. Following 
Table I. Patient characteristics at baseline in control, T2DM and DN uremia groups.

\begin{tabular}{|c|c|c|c|c|}
\hline Characteristic & Control & T2DM & DN uremia & P-value \\
\hline Male/female & $10 / 10$ & $15 / 13$ & $16 / 14$ & 0.845 \\
\hline Age (years) & $49 \pm 6$ & $52 \pm 8$ & $53 \pm 7$ & 0.249 \\
\hline Diabetes duration (years) & & $4.4 \pm 1.9$ & $4.5 \pm 1.6$ & \\
\hline Body mass index $\left(\mathrm{kg} / \mathrm{m}^{2}\right)$ & $23.1 \pm 1.9$ & $22.4 \pm 3.1$ & $23.6 \pm 4.2$ & 0.066 \\
\hline HBAlc $(\%)$ & $5.6 \pm 0.5$ & $5.8 \pm 0.6$ & $5.7 \pm 0.6$ & 0.413 \\
\hline Fasting glucose (mmol/l) & $5.5 \pm 0.9$ & $5.9 \pm 0.8$ & $5.8 \pm 0.7$ & 0.182 \\
\hline SBP (mmHg) & $134 \pm 6$ & $136 \pm 9$ & $140 \pm 9^{\mathrm{a}, \mathrm{b}}$ & 0.036 \\
\hline $\mathrm{DBP}(\mathrm{mmHg})$ & $76 \pm 9$ & $76 \pm 8$ & $80 \pm 10$ & 0.194 \\
\hline TG (mmol/l) & $1.6 \pm 0.5$ & $1.9 \pm 0.7$ & $1.5 \pm 0.5$ & 0.394 \\
\hline $\mathrm{TC}(\mathrm{mmol} / \mathrm{l})$ & $4.2 \pm 0.6$ & $4.2 \pm 0.8$ & $4.6 \pm 0.9$ & 0.063 \\
\hline LDL-c (mmol/l) & $2.6 \pm 0.6$ & $2.2 \pm 0.6^{\mathrm{a}}$ & $2.6 \pm 0.6$ & 0.034 \\
\hline HDL-c (mmol/l) & $1.2 \pm 0.5$ & $1.1 \pm 0.2$ & $1.1 \pm 0.5$ & 0.777 \\
\hline BUN (mmol/l) & $5.6 \pm 0.7$ & $5.7 \pm 1.5$ & $17.6 \pm 4.3^{c, d}$ & $<0.01$ \\
\hline $\mathrm{SCr}(\mu \mathrm{mol} / \mathrm{l})$ & $69.0 \pm 9.1$ & $68.1 \pm 14.6$ & $740.3 \pm 130.4^{\mathrm{c}, \mathrm{d}}$ & $<0.01$ \\
\hline WBC (x109/1) & $5.9 \pm 0.7$ & $5.4 \pm 1.4$ & $5.8 \pm 1.0$ & 0.183 \\
\hline $\mathrm{N}\left(\mathrm{x} 10^{9} / 1\right)$ & $3.0 \pm 0.4$ & $2.9 \pm 0.6$ & $3.3 \pm 0.6$ & 0.051 \\
\hline $\mathrm{M}\left(\mathrm{x} 10^{9} / 1\right)$ & $0.3 \pm 0.1$ & $0.3 \pm 0.1$ & $0.3 \pm 0.1$ & 0.873 \\
\hline 24 h UALB (mg/l) & $17.2 \pm 2.6$ & $19.5 \pm 5.3$ & $1719.3 \pm 373.1^{\mathrm{c}, \mathrm{d}}$ & $<0.01$ \\
\hline $25(\mathrm{OH}) \mathrm{VD}(\mathrm{ng} / \mathrm{ml})$ & $45.1 \pm 7.2$ & $24.8 \pm 2.6^{c}$ & $23.9 \pm 2.6^{c}$ & $<0.01$ \\
\hline GADA & $0.3 \pm 0.1$ & $0.4 \pm 0.1$ & $0.4 \pm 0.1$ & 0.188 \\
\hline CRP (mg/l) & $1.7 \pm 0.7$ & $3.3 \pm 1.6^{\mathrm{c}}$ & $5.4 \pm 2.8^{\mathrm{c}, \mathrm{d}}$ & $<0.01$ \\
\hline ET (EU/ml) & $0.03 \pm 0.01$ & $0.10 \pm 0.05^{\mathrm{c}}$ & $0.28 \pm 0.13^{\mathrm{c}, \mathrm{d}}$ & $<0.01$ \\
\hline
\end{tabular}

${ }^{\mathrm{a}} \mathrm{P}<0.05$ vs. healthy subjects (healthy control group); ${ }^{\mathrm{b}} \mathrm{P}<0.05 \mathrm{vs}$. $\mathrm{T} 2 \mathrm{DM}$ group; ${ }^{\mathrm{C}} \mathrm{P}<0.01 \mathrm{vs}$. healthy subjects (healthy control group); ${ }^{\mathrm{d}} \mathrm{P}<0.01$ vs. T2DM group. Values are expressed as the mean \pm standard deviation. T2DM, type 2 diabetes; DN, diabetic nephropathy; BMI, body mass index; HBA1c, hemoglobin A1c; TG, triglyceride; TC, total cholesterol; LDL-c, low-density lipoprotein-cholesterol; HDL- c, high-density lipoprotein-cholesterol; SBP, systolic blood pressure; DBP, diastolic blood pressure; WBC, white blood cells; N, neutrophils; M, monocytes; BUN, blood urea nitrogen; SCr, serum creatinine; 24 hUALB, 24-h urinary albumin excretion; 25 (OH) VD, 25-hydroxy vitamin D; GADA, glutamic acid decarboxylase antibody; CRP, C-reactive protein; ET, endotoxin.

culture with or without VD3 $\left(10^{-7} \mathrm{~mol} / \mathrm{l}\right)$ for $48 \mathrm{~h}$, LPS and human recombinant IL-15 were added at final concentrations of $1 \mu \mathrm{g} / \mathrm{ml}$ and $100 \mathrm{ng} / \mathrm{ml}$, respectively, followed by incubation for another $4 \mathrm{~h}$. The concentrations of serum, VD3, LPS and human recombinant IL-15 were optimized in preliminary experiments with the conditions used by previous studies as guidelines $(21,22)$. Monocytes and supernatants were then collected for subsequent analyses.

THP-1 monocyte cell viability assay. Trypan blue and the MTT method were used to detect the influence of serum, LPS, human recombinant IL-15 and VD3 on the cell viability. Under all experimental conditions, the cell viability was $>95 \%$.

Reverse transcription quantitative polymerase chain reaction analysis (RT-qPCR). TRIzol (Invitrogen; Thermo Fisher Scientific, Inc.) was used to extract total cellular RNA followed by determination of purity and content of RNA. The RNA was reversely transcribed into cDNA.

According to the mRNA sequences from GenBank, primers were synthesized by Takara Biotechnology Co., Ltd. (Dalian, China) and $\beta$-actin (132 bp) was set as an internal reference. The sequences of the primers were as follows:
TLR4 upstream, 5'-CGGTCCTCAGTGTGCTTGTAGTA-3' and downstream, 5'-CATTCCTTACCCAGTCCTCATCC-3', with a 162-bp amplified fragment; TLR9 upstream, 5'-AGATGGAGGGGAGAAGGTCTG-3' and downstream, 5'-CAAGGTGAAGTTGAGGGTGCT-3', with a 112-bp amplified fragment; IL-15 upstream, 5'-GCAATGAAGTGCTTTCTCTTGGA-3' and downstream, 5'-TTTTCCTCCAGTTCCTCACATTC-3', with a 167-bp amplified fragment; $\beta$-actin upstream, 5'-CCACGAAACTACCTTCAACTCC-3' and downstream, 5'-GTGATCTCCTTCTGCATCCTGT-3', with a 132-bp amplified fragment. The reaction conditions were: Pre-denaturation for $5 \mathrm{~min}$ at $94^{\circ} \mathrm{C}$, followed by 35 cycles of denaturation for $30 \mathrm{sec}$ at $94^{\circ} \mathrm{C}$, annealing for $30 \mathrm{sec}$ at $57^{\circ} \mathrm{C}$, extension for $30 \mathrm{sec}$ at $72^{\circ} \mathrm{C}$ and a final extension step of $5 \mathrm{~min}$ at $72^{\circ} \mathrm{C}$.

$\beta$-Actin (as the internal reference), together with the target genes, were subjected to PCR, and at the end of the reaction, the results were analyzed following SDS-PAGE (1.5\%; Biowest, Barcelona, Spain) and melting curve analysis was performed using CFX Manager (Bio-Rad Laboratories, Inc., Hercules, CA, USA). The relative expression of target genes in the samples was calculated from the cycle threshold (CT) values according to the following equations: $\Delta \mathrm{CT}=\mathrm{CT}_{\text {target gene }}-\mathrm{CT}_{\text {internal reference }}$; and 
Table II. Influence of LPS and IL-15 on levels of monocyte IL-15, TLR4 and TLR9 mRNA expression in each group.

\begin{tabular}{llll}
\hline Group & IL-15 & TLR4 & TLR9 \\
\hline Control group & $0.78 \pm 0.36$ & $1.09 \pm 0.58$ & $0.63 \pm 0.29$ \\
T2DM group & $1.29 \pm 0.63^{\mathrm{a}}$ & $3.24 \pm 1.09^{\mathrm{b}}$ & $0.57 \pm 0.23$ \\
DN uremia group & $1.81 \pm 0.65^{\mathrm{b}, \mathrm{c}}$ & $4.61 \pm 1.35^{\mathrm{b}, \mathrm{d}}$ & $0.54 \pm 0.22$ \\
\hline
\end{tabular}

${ }^{\mathrm{a}} \mathrm{P}<0.05$; ${ }^{\mathrm{P}} \mathrm{P}<0.01$, vs. the control group; ${ }^{\mathrm{C}} \mathrm{P}<0.01,{ }^{\mathrm{d}} \mathrm{P}<0.05$ vs. T2DM group. Values are expressed as the mean \pm standard deviation. LPS, lipopolysaccharide; IL, interleukin; TLR, Toll-like receptor; T2DM, type 2 diabetes; DN, diabetic nephropathy.

Table III. Influence of 1,25-dihydroxyvitamin D3 pre-treatment on IL-15, TLR4 and TLR9 mRNA expression in monocytes treated with lipopolysaccharide and IL-15 in each group.

\begin{tabular}{lccc}
\hline Group & IL-15 & TLR4 & TLR9 \\
\hline Control group & $0.69 \pm 0.28$ & $1.00 \pm 0.34$ & $0.68 \pm 0.28$ \\
T2DM group & $0.70 \pm 0.24$ & $1.18 \pm 0.37$ & $0.72 \pm 0.25$ \\
DN uremia group & $0.60 \pm 0.28$ & $0.96 \pm 0.35$ & $0.65 \pm 0.29$ \\
\hline
\end{tabular}

Values are expressed as the mean \pm standard deviation. IL, interleukin; TLR, Toll-like receptor; T2DM, type 2 diabetes; DN, diabetic nephropathy.

$\Delta \Delta \mathrm{CT}=\left(\mathrm{CT}_{\text {target gene }}-\mathrm{CT}_{\text {internal reference }}\right)$ of the patients $-\left(\mathrm{CT}_{\text {target gen }}\right.$ $\left.\mathrm{e}^{-}-\mathrm{CT}_{\text {internal reference }}\right)$ of the control group. The relative total amount of target genes was $2^{-\Delta \Delta \mathrm{CT}}$. The CT value refers to the number of cycles required for the fluorescence signal in each reaction tube to reach a set threshold. The CT value is negatively correlated with the level of target gene mRNA.

Western blot analysis of the protein expression of $N F-\kappa B$ p 65 and inhibitor of $N F-\kappa B(I \kappa B)$. Cells were lysed using TRIzol lysis buffer on ice and centrifuged at $12,000 \mathrm{~g}$ at $-4^{\circ} \mathrm{C}$ for $5 \mathrm{~min}$. The protein concentration in the supernatants was detected using a Bicinchoninic Acid Assay kit (cat. no. P0012; Beyotime Institute of Biotechnology, Haimen, China). The total protein $(50 \mu \mathrm{g})$ was separated by $12 \%$ SDS-PAGE, electrophoretically transferred onto polyvinylidene difluoride membranes and blocked with Tris-buffered saline containing Tween 20 and 5\% skimmed milk (Boster Systems, Inc., Pleasanton, CA, USA) for $90 \mathrm{~min}$. Membranes were incubated with rabbit anti-human $\mathrm{NF}-\kappa \mathrm{B}$ p65 antibodies (1:400) and mouse anti-human I $\mathrm{B}$ antibodies (1:400) (both from Santa Cruz Biotechnology, Inc. Dallas, TX, USA) or rabbit anti-mouse $\beta$-actin antibodies (1:1,500; Beijing 4A Biotechnology) overnight at $4^{\circ} \mathrm{C}$. The membranes were then washed and incubated with horseradish peroxidase-labeled goat anti-mouse and goat anti-rabbit immunoglobulin G (1:1500, Zhongshan Golden Bridge Biotechnology, Beijing, China) at room temperature for $2 \mathrm{~h}$. The membranes were washed, developed and fixed (BeyoECL Plus; cat. no. P0018; Beyotime Institute of Biotechnology), followed by capturing and analysis of images using an automated chemiluminescence imaging system (ChimDoc XRS; Bio-Rad Laboratories, Inc.).

Cytokine detection by ELISA. After intervention, the levels of IL-6 and monocyte chemoattractant protein 1 (MCP-1) in monocyte supernatants were detected by ELISA (BioSource
Pharm, Inc., New York, NY, USA). The optical density value of each well was detected at a wavelength of $450 \mathrm{~nm}$, and IL-6 and MCP-1 were expressed in $\mathrm{pg} / \mathrm{ml}$. Coefficients of variation of the intra-batch and inter-batch analyses were $<10 \%$. Each sample was measured in triplicate.

Statistical analysis. SPSS 15.0 (SPSS, Inc., Chicago, IL, USA) statistical software was used for statistical analysis. Values are expressed as the mean \pm standard deviation. Paired comparisons were performed using a paired $t$-test, and multiple group comparisons were performed using one-way analysis of variance. $\mathrm{P}<0.05$ was considered to indicate a statistically significant difference between values.

\section{Results}

Patient characteristics. There was no difference in the age, gender, body mass index, HBA1c levels, fasting blood glucose, diastolic blood pressure, triglyceride levels, total cholesterol, high-density lipoprotein, absolute leukocyte and monocyte count and GADA among the three groups ( $>>0.05)$. However, systolic blood pressure, kidney function and high-sensitivity C-reactive protein were significantly different between the control, T2DM and DN groups $(\mathrm{P}<0.01$; Table I).

Effects of LPS and IL-15 on the mRNA expression of IL-15, TLR4 and TLR9 in THP-1 monocytes in each group. After treatment with LPS + IL-15 for $4 \mathrm{~h}$, the levels of monocyte mRNA in the T2DM and DN uremia groups were significantly higher than those in the control group $(\mathrm{P}=0.046$ and 0.008 , respectively); the levels of TLR4 mRNA were also significantly higher than those in the control group $(\mathrm{P}=0.006$ and 0.002 , respectively). The levels of IL-15 and TLR4 mRNA in the DN group were significantly higher than those in the T2DM group ( $\mathrm{P}=0.015$ and 0.038 , respectively). 


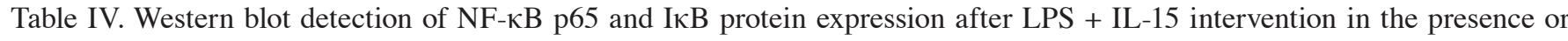
absence of VD3.

\begin{tabular}{|c|c|c|c|c|}
\hline \multirow[b]{2}{*}{ Group } & \multicolumn{2}{|c|}{$\mathrm{NF}-\kappa \mathrm{B}$ p65 } & \multicolumn{2}{|c|}{$\mathrm{I} \kappa \mathrm{B}$} \\
\hline & $\begin{array}{l}\text { LPS + IL-15 } \\
\text { intervention }\end{array}$ & $\begin{array}{c}\text { VD3 } \\
\text { pre-treatment }\end{array}$ & $\begin{array}{l}\text { LPS + IL-15 } \\
\text { intervention }\end{array}$ & $\begin{array}{c}\text { VD3 } \\
\text { pre-treatment }\end{array}$ \\
\hline Control group & $0.26 \pm 0.14$ & $0.36 \pm 0.12$ & $0.98 \pm 0.19$ & $0.18 \pm 0.09$ \\
\hline T2DM group & $0.38 \pm 0.26^{\mathrm{a}}$ & $0.31 \pm 0.11$ & $0.49 \pm 0.17^{b}$ & $0.21 \pm 0.13$ \\
\hline DN uremia group & $0.65 \pm 0.13^{\mathrm{a}, \mathrm{c}}$ & $0.40 \pm 0.14$ & $0.24 \pm 0.12^{\mathrm{a}, \mathrm{d}}$ & $0.17 \pm 0.08$ \\
\hline
\end{tabular}

${ }^{\mathrm{a}} \mathrm{P}<0.01,{ }^{\mathrm{b}} \mathrm{P}<0.05$ vs. the control group; ${ }^{\mathrm{c}} \mathrm{P}<0.05$; ${ }^{\mathrm{d}} \mathrm{P}<0.01$ vs. T2DM group. Values are expressed as the mean \pm standard deviation. IL, inter-

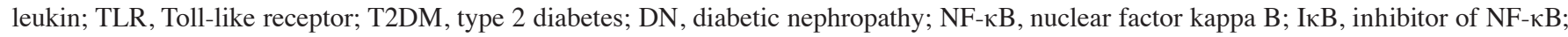
LPS, lipopolysaccharide; VD3, 1,25-dihydroxyvitamin D3.
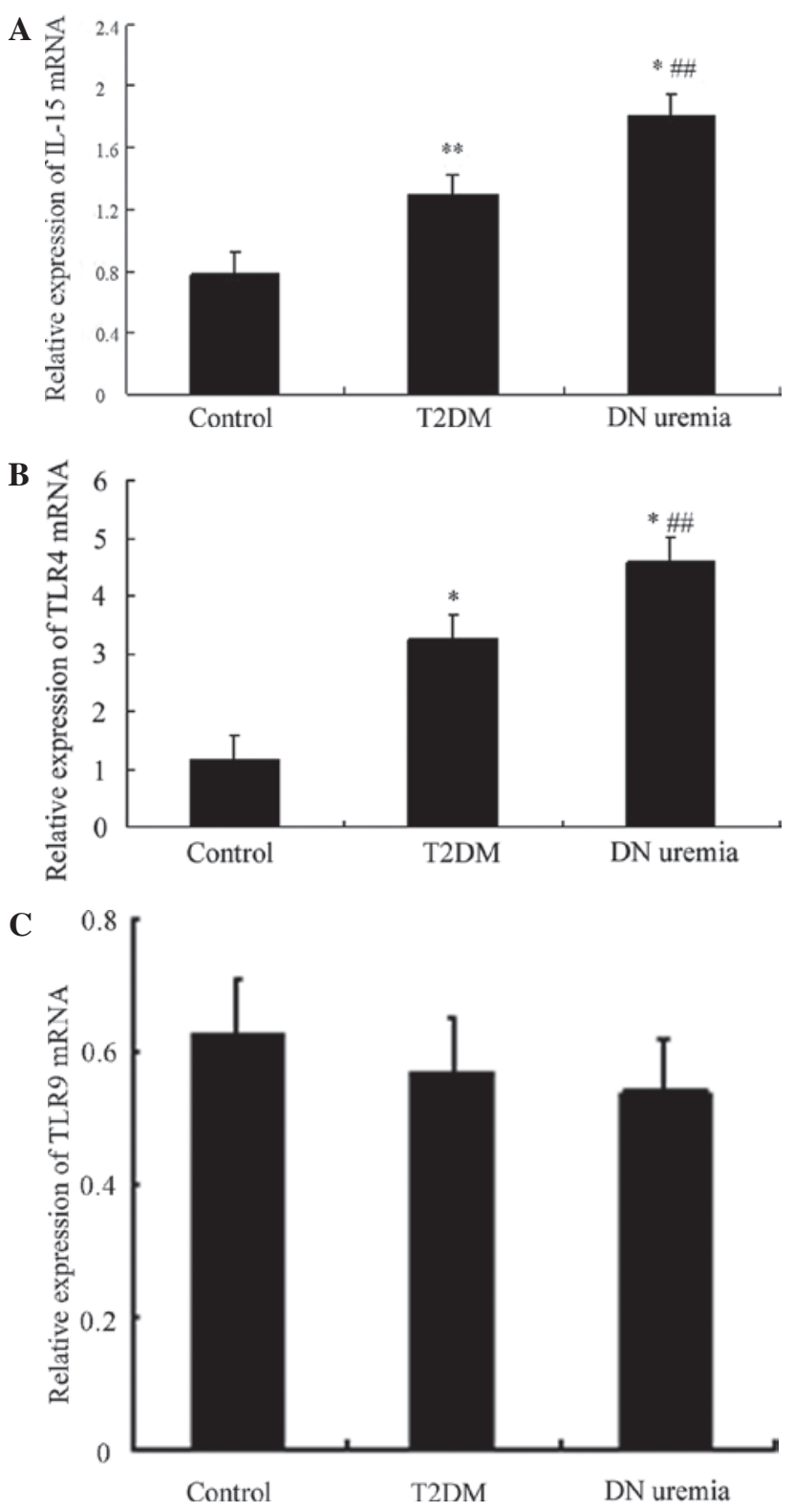

Figure 1. Influence of lipopolysaccharide and IL-15 on levels of monocyte IL-15, TLR4 and TLR9 mRNA in each group. (A) IL-15 mRNA expression. (B) TLR4 mRNA expression. (C) TLR9 mRNA expression. Values are expressed as the mean \pm standard deviation. ${ }^{*} \mathrm{P}<0.01,{ }^{* *} \mathrm{P}<0.05$ vs. the control group; ${ }^{\# \#} \mathrm{P}<0.05$ vs. the former. IL, interleukin; TLR, Toll-like receptor; T2DM, type 2 diabetes; DN, diabetic nephropathy.
However, there was no significant difference in the levels of TLR9 mRNA among the three groups (P>0.05) (Fig. 1 and Table II).

VD3 does not affect IL-15, TLR4 and TLR9 mRNA expression in THP-1 monocytes treated with LPS and IL-15. As shown in Table III, pre-treatment with VD3 did not affect the mRNA levels of IL-15, TLR4 and TLR9 following treatment with LPS and IL-15 in each group ( $\mathrm{P}>0.05)$.

Effects of VD3 on NF- $\kappa B$ p 65 and I $\kappa$ B protein expression in LPS + IL-15-treated THP-1 monocytes. After treatment with LPS and IL-15, the protein levels of NF- $\kappa$ B p65 in THP-1 monocytes from the T2DM and DN uremia groups was upregulated, compared with those in the control group ( $\mathrm{P}=0.009$ and 0.002 , respectively), and they were higher in the $\mathrm{DN}$ uremia group than those in the T2DM group $(\mathrm{P}=0.016)$. However, I $\kappa \mathrm{B}$ protein expression showed an opposite trend to

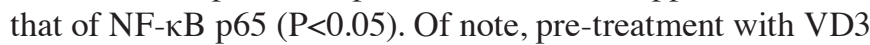
blocked LPS + IL-15-induced increases in NF- $\kappa \mathrm{B}$ p 65 protein and decreases in $\mathrm{I} \kappa \mathrm{B}$, and after VD3 intervention, NF- $\kappa \mathrm{B}$ p65 and $\mathrm{I} \kappa \mathrm{B}$ levels in the control, T2DM and DN uremia groups showed no significant difference $(\mathrm{P}>0.05)$ (Fig. 2 and Table IV).

VD3 pre-treatment on IL-6 and MCP-1 expression in monocyte supernatants after treatment with $L P S+I L-15$. As shown in Fig. 3, after LPS + IL-15 treatment, the levels of IL-6 and MCP-1 in the supernatants of monocytes cultured in the presence of serum from patients with DN uremia (248.87 $\pm 54.69 \mathrm{pg} / \mathrm{ml}$ and $95.40 \pm 16.68 \mathrm{pg} / \mathrm{ml}$, respectively) or T2DM $(157.55 \pm 26.38 \mathrm{pg} / \mathrm{ml}$ and $37.07 \pm 11.08 \mathrm{pg} / \mathrm{ml}$, respectively) were significantly higher than those in the control group $(78.33 \pm 16.95$ and $26.02 \pm 8.12 \mathrm{pg} / \mathrm{ml}$; $\mathrm{P}<0.01)$ (Fig. $3 \mathrm{~A}$ and B). Furthermore, the levels of IL- 6 in the DN group were significantly higher than those in the T2DM group $(\mathrm{P}<0.01)$ (Fig. 3A and B). Of note, pre-treatment with VD3 significantly decreased IL- 6 secretion by monocytes compared with that in the monocytes treated with LPS + IL-15 only. Following VD3 pre-treatment, no significant difference was found in the levels of IL-6 and MCP-1 among the T2DM, DN uremia and control groups ( $\mathrm{P}>0.05)$ (Fig. 3C and D). 

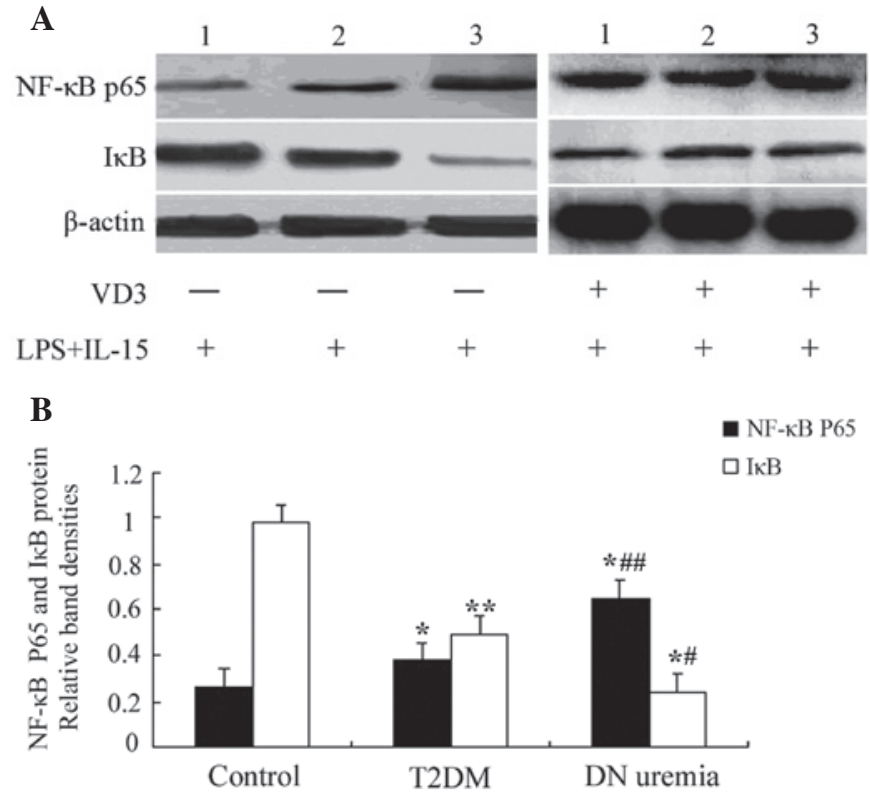

LPS+IL-15 intervention

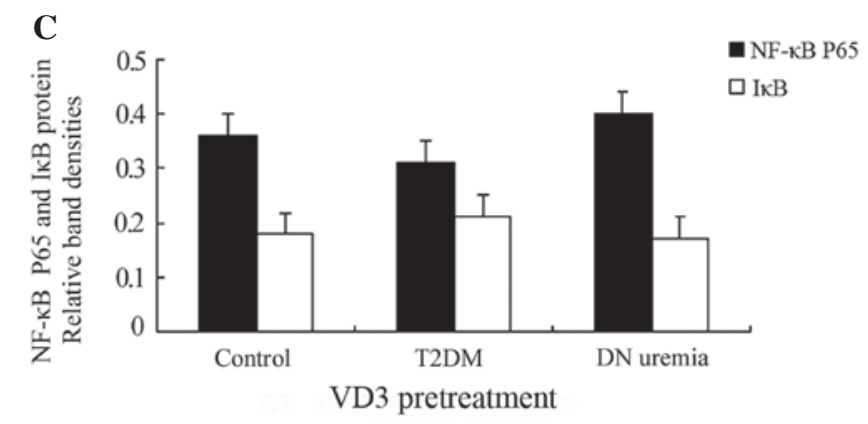

Figure 2. Western blot analysis of monocyte NF-кB p65 and IкB protein

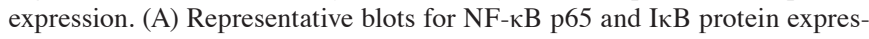
sion. Lanes: 1, Control group; 2, T2DM group; 3, DN uremia group. (B) Bar graph showing NF- $\kappa \mathrm{B}$ p65 and IкB protein expression in THP-1 monocytes treated with LPS and IL-15. (C) Bar graph showing NF-кB p65 and ІкB protein expression in THP-1 monocytes pre-treated with VD3; Values are expressed as the mean \pm standard deviation. ${ }^{*} \mathrm{P}<0.01,{ }^{* * *} \mathrm{P}<0.05$ vs. the control group; ${ }^{\#} \mathrm{P}<0.01,{ }^{\# \#} \mathrm{P}<0.05$ vs. the former. VD3, 1,25-dihydroxyvitamin $\mathrm{D} 3$; IL, interleukin; T2DM, type 2 diabetes; DN, diabetic nephropathy; NF-кB, nuclear factor kappa B; IкB, inhibitor of NF-кB; LPS, lipopolysaccharide.

\section{Discussion}

Inflammatory cytokines have been shown to participate in each stage of DN, and T2DM monocytes have a pro-inflammatory properties as well as a high potential for the expression of inflammatory cytokines (1). Circulating inflammatory markers are increased in patients with T1DM or T2DM, which may be caused by monocyte/macrophage infiltration in the kidneys. Therefore, according to the inflammatory immune theory, it is thought that DN is a chronic low-grade inflammatory disease characterized by natural immune activation (23-29). In recent years, the anti-inflammatory and immunomodulatory effects of VD3 have received extensive attention (30). Substantial studies have shown that VD3 causes decreases in TLR4 and NF- $\mathrm{\kappa B}$ expression (11-14) and a reduction in inflammatory cytokines secreted by monocytes (3). A previous study by our group showed that VD3 alleviates inflammation, which may be associated with
$\mathbf{A}$

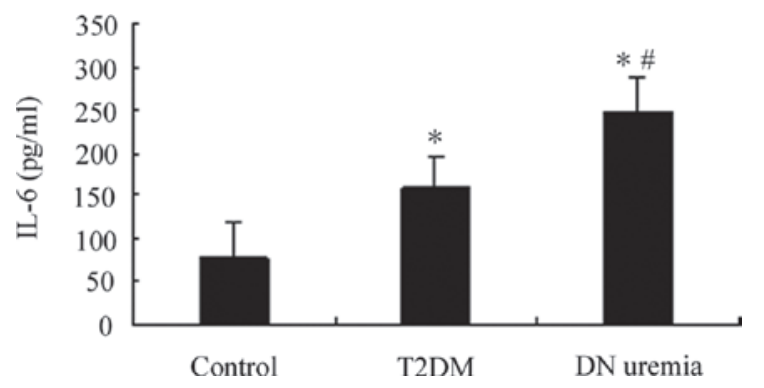

B

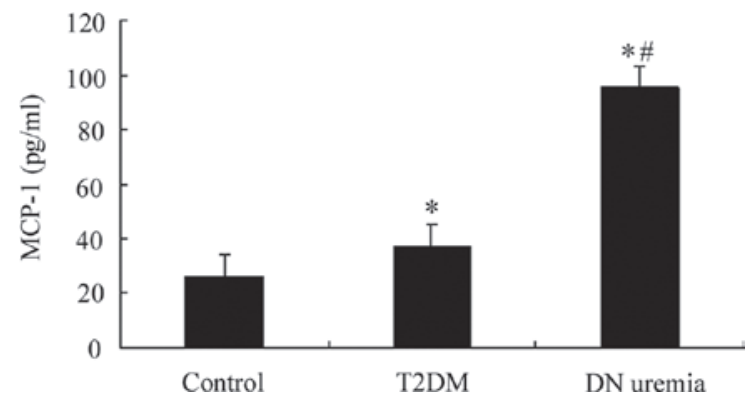

C

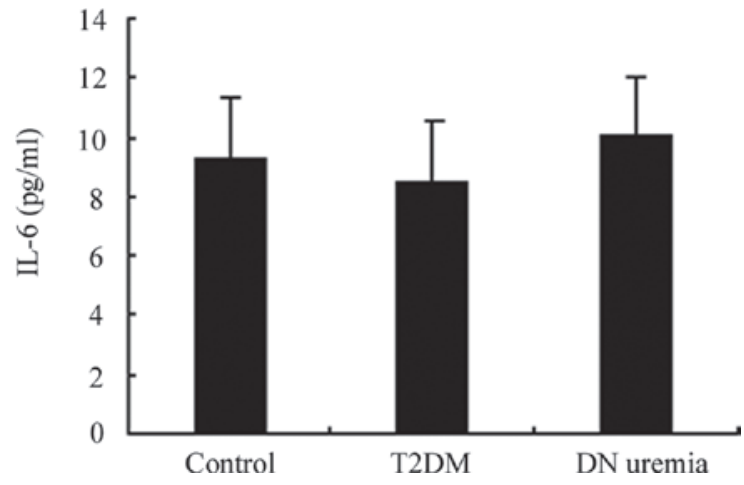

D

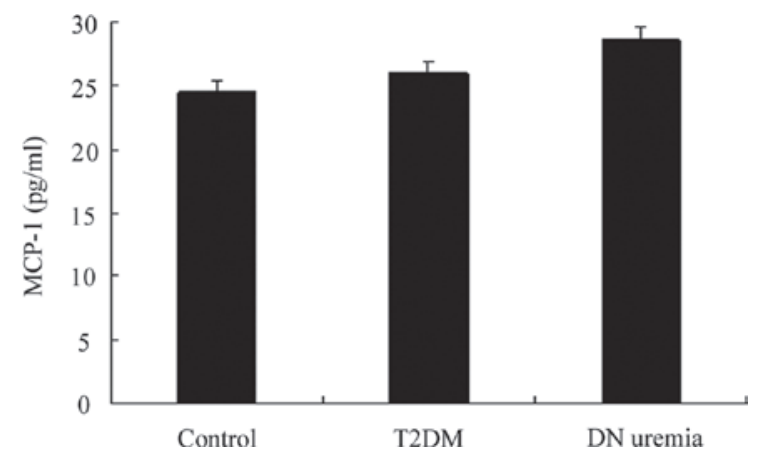

Figure 3. IL-6 levels in the supernatant of VD3- and/or LPS + IL-15-treated monocytes. (A) IL-6 levels after LPS and IL-15 intervention; (B) MCP-1 levels after LPS and IL-15 intervention; (C) IL-6 levels after VD3 pre-treatment; (D) MCP-1 levels after VD3 pre-treatment. Values are expressed as the mean \pm standard deviation. ${ }^{~} \mathrm{P}<0.01,{ }^{* * *} \mathrm{P}<0.05$ vs. the control group; ${ }^{\prime} \mathrm{P}<0.01$, ${ }^{\# \#} \mathrm{P}<0.05$ vs. the former. VD3, 1,25-dihydroxyvitamin D3; IL, interleukin; T2DM, type 2 diabetes; DN, diabetic nephropathy; LPS, lipopolysaccharide; MCP-1, monocyte chemoattractant protein-1.

STAT5-VDR crosstalk in monocytes (14). However, it has remained elusive whether the anti-inflammatory effects of VD3 in monocytes from T2DM and DN uremic patients are mediated via the TLR4/NF- $\mathrm{BB}$ signaling pathway. Based on previous studies by our and other groups (19,31-33), the present study hypothesized that the anti-inflammatory effects of VD3 on monocytes from T2DM and DN uremic patients may be associated with the TLR4/NF- $\mathrm{KB}$ signaling pathway and performed experiments to verify this hypothesis. 
The present study found that, compared with those in the control group, the mRNA expression of IL-15 and TLR4, the protein expression of $\mathrm{NF}-\kappa \mathrm{B}$ p 65 and the pro-inflammatory mediators IL-6 and MCP-1 in the supernatant of monocytes incubated with serum from T2DM and DN patients were all significantly upregulated following treatment with LPS + IL-15. Furthermore, the levels of IL-15 and TLR4 mRNA, NF- $\kappa$ B p65 protein, and the secretion of IL- 6 and MCP-1 in the DN uremia group were all higher than those in the T2DM group. These results, which were consistent with findings of previous studies (9-12), indicated that the sensitivity of monocytes treated with serum from T2DM and DN patients to LPS and IL-15 was elevated. The mechanisms of this effect are likely to include the TLR4/NF- $\mathrm{BB}$ signaling pathway, as LPS and IL-15 stimulated the expression of TLR4 and NF- $\kappa$ B.

As shown in Tables III and IV, the present study also showed that VD3 pre-treatment for $48 \mathrm{~h}$ significantly attenuated the effects of LPS + IL-15 stimulation; VD3 was able to block the pro-inflammatory effects of LPS and IL-15 by inhibiting increases in the levels of IL-15, TLR4 mRNA and NF- $\kappa$ B p65 protein expression as well as the secretion of pro-inflammatory mediators IL-6 and MCP-1 in the supernatant. These findings are in accordance with the findings of previous studies (9-11), indicating that VD3 is able to alleviate inflammation. However, pre-treatment with VD3 followed by LPS + IL-15 had no significant effect on the mRNA expression of TLR-9 in the three groups. Therefore, the anti-inflammatory effects of VD3 on monocytes cultured in sera of patients with T2DM and DN uremia may be associated with the TLR4/NF- $\kappa B$ signaling pathway.

The present study had certain limitations, including a small sample size. Moreover, the present study only observed the anti-inflammatory effects of VD3 in patients with T2DM and DN uremia in vitro, which may not be representative of the in vivo micro-environment. The findings of the present study should further validated by expanding the sample size and performing animal studies.

In conclusion, the present study preliminarily investigated the influence of VD3 and LPS + IL-15 on TLR4 and NF- $\mathrm{BB}$ expression in monocytes incubated with serum from T2DM and DN uremic patients, and explored the mechanism of action of VD3 against the inflammatory immune response of T2DM and DN. The results indicated that VD3 may exert its anti-inflammatory effects via the TLR4/NF- $\kappa \mathrm{B}$ signaling pathway. Supplementation of DM and DN patients as well as other individuals who are also susceptible to vitamin D3 deficiency, with active vitamin D3 may be suitable for the prevention and treatment of T2DM and DN. The use of vitamin $\mathrm{D}$ and its derivatives in the prevention and treatment of DM is desirable, as it would reduce the high cost of DM treatment, due to vitamin D being inexpensive as well as easy to administer. Therefore, future studies by our group will perform an in-depth analysis of the abovementioned pathway in order to provide novel clues for the prevention and treatment for T2DM and DN.

\section{Acknowledgements}

The authors would like to thank Professor Qifu Li and Dr Lai Han for their cooperation in patient selection. National
Natural Science Foundation of China (grant. no. 81560147), the Science and Technology Project of Guizhou Province [grant. no. SY (2012) No. 3116), the Science and Technology Fund Project of Guizhou Province [grant. no. J word LKZ(20 13) No. 53], the Doctoral Fund of the Zunyi Medical College (grant. no. F-588) and the Outstanding Doctoral Dissertation Fund of Chongqing Medical University, supported by the Key Project of Chongqing Municipal Health Bureau (grant. no. 2010-1-16).

\section{References}

1. Pickup JC: Inflammation and activated innate immunity in the pathogenesis of type 2 diabetes. Diabetes Care 27: 813-823,2004.

2. Baeke F, Korf H, Overbergh L, van Etten E, Verstuyf A, Gysemans $C$ and Mathieu C: Human T lymphocytes are direct targets of 1,25-dihydroxy1,25(OH)2D3 in the immune system. J Steroid Biochem Mol Biol 121: 221-227, 2010.

3. Thacher TD and Clarke BL: Vitamin D insufficiency. Mayo Clin Proc 86: 50-60, 2011.

4. Giulietti A, van Etten E, Overbergh L, Stoffels K, Bouillon R and Mathieu C: Monocytes from type 2 diabetic patients have a pro-inflammatory profile 1, 25-dihydroxyvitamin D3 works as anti-inflammatory. Diabetes Res Clin Pract 77: 47-57, 2007.

5. Du T, Zhou ZG, You S, Huang G, Lin J, Yang L, Li X, Zhou WD and Chao C: Modulation of monocyte hyperresponsiveness to TLR ligands by 1,25-dihydroxy-vitamin D3 from LADA and T2DM. Diabetes Res Clin Pract 83: 208-214, 2009.

6. Liu PT, Steffen S, Li H, Wenzel L, Tan BH, Krutzik SR, Ochoa MT, Schauber J, Wu K, Meinken C, et al: Toll-like receptor triggering of a vitamin $\mathrm{D}$ mediated human antimicrobial response. Science 311: 1770-1773, 2006.

7. Nimitphong H, Holick MF, Fried SK and Lee MJ: 25-hydroxyvitamin $\mathrm{D}_{3}$ and 1,25-dihydroxyvitamin $\mathrm{D}_{3}$ promote the differentiation of human subcutaneous preadipocytes. PLoS One 7: e52171, 2012

8. Kim F, Pham M, Luttrell I, Bannerman DD, Tupper J, Thaler J, Hawn TR, Raines EW and Schwartz MW: Toll-like receptor 4 mediates vascular inflammation and insulin resistance in diet-induced obesity. Circ Res 100: 1589-1596, 2007.

9. Devaraj S, Dasu MR, Rockwood J, Winter W, Griffen SC and Jialal I: Increased Toll-like receptor (TLR) 2 and TLR4 expression in monocytes from patients with type 1 diabetes: further evidence of a proinflammatory state. J Clin Endocrinol Metab 93: 578-583, 2008.

10. Dasu MR, Devaraj S, Park S and Jialal I: Increased Toll-like receptor (TLR) activation and TLR ligands in recently diagnosed Type 2 diabetic subjects. Diabetes Care 33: 861-868, 2010.

11. Verma R, Jung JH and Kim JY: 1,25-Dihydroxyvitamin D3 up-regulates TLR10 while down-regulating TLR2, 4 and 5 in human monocyte THP-1. J Steroid Biochem Mol Biol 141: 1-6, 2014.

12. Sadeghi K, Wessner B, Laggner U, Ploder M, Tamandl D, Friedl J, Zügel U, Steinmeyer A, Pollak A, Roth E, et al: Vitamin D3 down-regulates monocyte TLR expression and triggers hyporesponsiveness to pathogen-associated molecular patterns. Eur J Immunol 36: 361-370, 2006.

13. Gu HR, Luan B, Qiao JY, Wang YZ and Li Q: Effect of 1,25-(OH)2D3 on expression of HMGB1 and TLR4 in the lungs of asthmatic mice. Zhongguo Dang Dai Er Ke Za Zhi 16: 301-305, 2014 (In Chinese).

14. Li F, Liu P, Zhang X, Zhang Q, Tang S, Zhu M and Qiu M: $1,25(\mathrm{OH}) 2 \mathrm{D} 3$-mediated amelioration of aortic injury in streptozotocin-induced diabetic rats. Inflammation 36: 1334-1343, 2013.

15. Yang M, Gan H, Shen Q, Tang W, Du X and Chen D: Proinflammatory CD14+CD16+monocytes are associated with microinflammation in patients with type 2 diabetes mellitus and diabetic nephropathy uremia. Inflammation 35: 388-396, 2012.

16. Yang M, Shen Z, Chen D, et al: Effects of 1,25-(OH)2D3 on the expressions of vitamin D receptor, STAT5 and cytoskeletal rearrangement in human monocytes incubated with sera from type 2 diabetes patients and diabetic nephropathy patients with uremia. Inflamm Res 61: 511-520, 2012. 
17. Yang M, Gan H, Shen Q, et al: Proportion of CD14+CD16+ monocytes in peripheral blood from patients with type 2 diabetic mellitus and effect of LPS and IL-15 on expression of STAT5 in monocytes. Chinese Pathophysiology 1: 136-141, 2012.

18. Alleva DG, Kaser SB, Monroy MA, Fenton MJ and Beller DI: IL-15 functions as a potent autocrine regulator of macrophage proinflammatory cytokine production: Evidence for differential receptor subunit utilization associated with stimulation or inhibition. J Immunol 159: 2941-2951, 1997.

19. Yao L, Xiao Y, Liu SP, Xu AM and Zhou ZG: Serum of obesity induce the activation of TLR4/NF- $\kappa B$ signaling pathway on THP-1 cell line. Zhonghua Yi Xue Za Zhi 90: 3119-3123, 2010 (In Chinese).

20. Ge JB and Xu YJ: Internal Medicine (Edition 8). People Health Publishing House, Beijing, p. 741, 2013.

21. Pramanik R, Asplin JR, Lindeman C, Favus MJ, BAi S and Coe FL: Lipopolysaccharide negatively modulates vitamin D action by down-regulating expression of vitamin D-induced VDR in human monocytic THP-1 cells. Cell Immunol 232: 137-143, 2004

22. Sadeghi K, Wessner B, Laggner U, Ploder M, Tamandl D, Friedl J, Zügel U, Steinmeyer A, Pollak A, Roth E, et al: Vitamin D3 down-regulates monocyte TLR expression and triggers hyporesponsiveness to pathogen-associated molecular patterns. Eur J Immunol 36: 361-370, 2006.

23. Navarro-González JF and Mora-Fernández C: The role of inflammatory cytokines in diabetic nephropathy. J Am Soc Nephrol 19: 433-442, 2008

24. Ortiz-Muñoz G, Lopez-Parra V, Lopez-Franco O, Fernandez-Vizarra P, Mallavia B, Flores C, Sanz A, Blanco J, Mezzano S, Ortiz A, et al: Suppressors of cytokine signaling abrogate diabetic nephropathy. J Am Soc Nephrol 21: 763-772, 2010.
25. O'Connor JC, Satpathy A, Hartman ME, Horvath EM, Kelley KW, Dantzer R, Johnson RW and Freund GG: IL-1beta-mediated innate immunity is amplified in the $\mathrm{db} / \mathrm{db}$ mouse model of type 2 diabetes. J Immunol 174: 4991-4997, 2005.

26. Mora $\mathrm{C}$ and Navarro JF: Inflammation and diabetic nephropathy. Curr Diab Rep 6: 463-468, 2006.

27. Navarro JF and Mora C: Diabetes, inflammation, proinflammatory cytokines and diabetic nephropathy. Scientific World Journal 6: 908-917, 2006.

28. Tuttle KR: Linking metabolism and immunology: Diabetic nephropathyis an inflammatory disease. J Am Soc Nephrol 16: 1537-1538, 2005.

29. Ruster C and Wolf G: The role of chemokines and chemokine receptors in diabetic nephropathy. Front Biosci 13: 944-955, 2008.

30. Stubbs JR, Idiculla A, Slusser J, Menard R and Quarles LD: Cholecalciferol supplementation alters calcitriol-responsive monocyte proteins and decreases inflammatory cytokines in ESRD. J Am Soc Nephrol 21: 353-361, 2010.

31. Akira $S$ and Takeda K: Toll-like receptor signaling. Nat Rev Immunol 7: 499-511, 2004.

32. Cao XT: The Progress of Immunology. People's Medical Publishing House, Beijing, p143, 2009.

33. Li ML, Gan H and Qiao L: The expression of TLR4 on peripheral blood monocytes from uremic patients with diabetic nephropathy and its relation with plasma MCP-1 concentration. Chinese Journal of Immunology 9: 848-850, 2009 . 